\title{
The graded effect of hyperhomocysteinemia on the severity and extent of coronary atherosclerosis
}

\author{
Chia-Lun Chao a, Hui-Hsin Tsai ${ }^{b}$, Chii-Ming Lee ${ }^{a}$, Su-Ming Hsu ${ }^{b}$, Jau-Tsuen Kao ${ }^{\text {, }}$ \\ Kuo-Liong Chien a, Fung-Chang Sung ${ }^{\text {d }}$, Yuan-Teh Lee ${ }^{\text {a,* }}$
a Department of Internal Medicine (Cardiology), National Taiwan University Hospital, 7 Chung-Shan South Road, Taipei, 10016, Taiwan, ROC ${ }^{\mathrm{b}}$ Office for Research and Development, National Taiwan University Hospital, 7 Chung-Shan South Road, Taipei, 10016, Taiwan, ROC
${ }^{\mathrm{c}}$ School and Graduate Institute of Medical Technology, National Taiwan University College of Medicine, Taipei, Taiwan, ROC
${ }^{\mathrm{d}}$ National Taiwan University College of Public Health, Taipei, Taiwan, ROC

Received 6 November 1998; received in revised form 29 March 1999; accepted 25 May 1999

\begin{abstract}
It is not clear to what extent methylenetetrahydrofolate reductase (MTHFR) gene and hyperhomocysteinemia effect the severity and extent of coronary atherosclerosis in Asian populations. We examined the MTHFR genotypes and plasma homocysteine (HCY) concentrations in 192 Taiwanese and investigated their relationship with coronary artery disease (CAD), and the severity and extent of coronary atherosclerosis. The distribution of MTHFR genotypes was similar in 116 CAD patients and 76 non-CAD subjects. Homozygosity was noted in $8 \%$ of CAD patients and $13 \%$ of non-CAD subjects $(P=0.33 ; 95 \% \mathrm{CI}, 0.2-1.6)$. The geometric mean of HCY values was higher in CAD patients $(11.10 \pm 1.51 \mu \mathrm{mol} / \mathrm{l})$ than in non-CAD subjects $(9.21 \pm 1.55 \mu \mathrm{mol} / \mathrm{l})$ $(P=0.003)$. HCY levels were higher in patients with multi-vessel disease $(P<0.05)$ or in patients with $\geq 90 \%$ stenotic lesions $(P=0.005)$, compared with non-CAD subjects. The CAD risks in the top two HCY quartiles $(\geq 14.0$ and $10.1-13.9 \mu \mathrm{mol} / \mathrm{l})$ were $4.0(95 \%$ CI, 1.7-9.2) and $3.2(95 \%$ CI, 1.4-7.4) times higher than in the lowest quartile $(\leq 7.9 \mu \mathrm{mol} / 1)(P=0.001$ and 0.007 , respectively). Linear regression analysis showed significant correlations between HCY concentrations and the severity and extent of atherosclerosis $(P=0.0001$ for both). In conclusion, hyperhomocysteinemia appears to have a graded effect on the risk of CAD as well as the severity and extent of coronary atherosclerosis. Our findings do not support the homozygous genotype of MTHFR as a genetic risk factor for CAD in this Taiwanese population. Perhaps a further study including assessment of vitamin status is needed to better clarify the relationship between MTHFR genotypes and CAD. C 1999 Elsevier Science Ireland Ltd. All rights reserved.
\end{abstract}

Keywords: Hyperhomocysteinemia; Methylenetetrahydrofolate reductase; Coronary artery disease

\section{Introduction}

As an important risk factor for coronary atherosclerosis, elevated plasma homocysteine (HCY) concentration, has recently received greater attention than have conventional risk factors such as smoking, hypercholesterolemia, hypertension and diabetes mellitus [1,2]. The exact mechanism for high HCY concentrations leading to the development of atherosclerosis remains unclear. Possible mechanisms include the effect on platelets, clotting factors, and the endothelium [3].

\footnotetext{
* Corresponding author. Tel.: + 886-2-23959911, ext. 7777; fax: +886-2-23779168.

E-mail address: ytlee@ha.mc.ntu.edu.tw (Y.-T. Lee)
}

Hyperhomocysteinemia has been associated with genetic defects and/or nutrient deficiencies [4,5]. Methylenetetrahydrofolate reductase (MTHFR), the key enzyme in the remethylation of homocysteine to the methionine pathway, converting 5,10-methylenetetrahydrofolate into 5-methyltetrahydrofolate, has been reported to contribute to hyperhomocysteinemia with its thermolabile variant [6]. The MTHFR gene has been cloned [7], and several mutations were found in it [8]. One of the nucleotide mutations $(677 \mathrm{C} \rightarrow \mathrm{T}$; alanine to valine) commonly seen in the MTHFR gene in its homozygous state is responsible for the thermolabile phenotype and is associated with decreased MTHFR activity and an elevated fasting HCY concentration [9]. 
Although the presence of a homozygous mutation has been reported as a risk factor for coronary artery disease (CAD) [9-11], some suggest that mutation alone may not be an independent risk factor for CAD [12-14].

Increasing severity of carotid disease with increasing HCY levels has been seen in asymptomatic adults [15], but reports on the relationship between the severity of CAD and HCY levels have been conflicting. Kang et al. [16] reported no correlation between HCY concentrations and severity of coronary stenosis. However, von Eckardstein et al. [17] did show a correlation between HCY levels and the number of occluded coronary arteries. In addition to significant stenosis, major clinical coronary events may be related to the extent of angiographically minor plaque [18]. The correlation between HCY concentrations and the extent of coronary atherosclerosis needs further investigation.

Because cardiovascular disease is now a leading cause of death in Taiwan, we undertook the present study to determine the prevalence of the MTHFR $677 \mathrm{C} \rightarrow \mathrm{T}$ mutation and $\mathrm{HCY}$ concentrations in our population and investigated their relationship with CAD. To our knowledge, this is the first study to examine the relationship between HCY levels and the severity and extent of coronary atherosclerosis in an Asian population. Our data indicate that hyperhomocysteinemia, but not MTHFR mutation, appears to be associated with CAD and has a graded effect on the risk of CAD as well as the severity and extent of coronary atherosclerosis.

\section{Methods}

\subsection{Subjects}

With consent, 192 subjects underwent coronary angiography at the National Taiwan University Hospital in 1997. In addition to conventional lipid analysis, blood samples were obtained for MTHFR gene analysis and measurement of plasma HCY levels. The indications for cardiac catheterization were stable angina in $70(36 \%)$ individuals, unstable angina in $15(8 \%)$, prognostic stratification following myocardial infarction in $31(16 \%)$, atypical chest pain in $42(22 \%)$, and other reasons including valvular heart disease, cardiomyopathy, and congenital heart disease in 34 $(18 \%)$.

The coronary angiography was performed in multiple projections to assure full assessment of the anatomy and was recorded on $35-\mathrm{mm}$ cine films. The degrees of narrowing of the intraluminal diameters of the arteries were measured with the caliper method and by visual estimation by experienced angiographers who were unaware of the subjects' HCY and MTHFR gene status. CAD was defined as at least $70 \%$ stenosis in one or more of the three coronary arteries or their primary branches [19]. The severity score of coronary stenosis was obtained by use of the Gensini scoring system $[20,21]$. The extent score to estimate the percentage of the coronary artery involved in atheroma was obtained by the method described by Sullivan et al. [22].

\subsection{Genetic analysis}

Heparinized blood was collected at the time of angiography after $12 \mathrm{~h}$ of fasting. Leukocytes were isolated immediately from plasma. DNA extracted from frozen buffy coat cells by Instagene kit (Bio-Rad, USA) was stored at $-20^{\circ} \mathrm{C}$ until analysis, and plasma was stored at $-80^{\circ} \mathrm{C}$ for $\mathrm{HCY}$ determination. The DNA sample underwent the polymerase chain reaction (PCR) as described by Frosst et al. [9]. The primers for analysis of the $677 \mathrm{C} \rightarrow \mathrm{T}$ mutation were 5'TGAAGGAGAAGGTGTCTGCGGGA-3' and 5'AgGCGGTGCGgTGAGAGTG-3'. The PCR mixture $(50 \mu \mathrm{l})$ contained $50 \mathrm{ng}$ of genomic DNA, 20 pmol of each primer and $1 \mathrm{U}$ of Taq polymerase (Perkin-Elmer, USA). The cycle parameters were 3min initial denaturation at $94^{\circ} \mathrm{C}$, followed by 35 cycles of $40 \mathrm{~s}$ at $94^{\circ} \mathrm{C}, 45 \mathrm{~s}$ at $65^{\circ} \mathrm{C}$, and $45 \mathrm{~s}$ at $72^{\circ} \mathrm{C}$. Final extension was performed at $72^{\circ} \mathrm{C}$ for $7 \mathrm{~min}$. The amplified DNA fragment (198 bp) was then subjected to HinfI digestion and subsequent electrophoresis in a $4 \%$ agarose gel. The wild type remained $198 \mathrm{bp}$ after digestion and was designated as $\mathrm{C}$, whereas the mutant allele which could be digested into 175 and $23 \mathrm{bp}$ was designated as $\mathrm{T}$.

\subsection{Homocysteine determination}

The plasma was frozen at $-80^{\circ} \mathrm{C}$ until analysis. The measurement of HCY was based on the method described by Fortin and Genest [23]. Samples containing $180 \mu \mathrm{l}$ of plasma, $45 \mu \mathrm{l}$ of $2.5 \mathrm{mM}$ acetylcysteine, $0.9 \% \mathrm{NaCl}, 4 \mathrm{mM}$ EDTA, and $22.5 \mu \mathrm{l}$ of $10 \%$ Tri- $n$ butylphosphine in dimethylformamide were incubated at $4^{\circ} \mathrm{C}$ for $30 \mathrm{~min}$, and $225 \mu \mathrm{l}$ of $0.6 \mathrm{M}$ perchloric acid in $1 \mathrm{mM}$ EDTA was added. After centrifugation at $3000 \mathrm{rpm}$ for $5 \mathrm{~min}, 100 \mu \mathrm{l}$ of the supernatant was mixed with $20 \mu \mathrm{l}$ of $1.55 \mathrm{M} \mathrm{NaOH}, 250 \mu \mathrm{l}$ of $0.125 \mathrm{M}$ potassium tetraborate, $\mathrm{pH} 9.5$, containing $4 \mathrm{mM}$ EDTA, and $100 \mu \mathrm{l}$ of ammonium-7-fluorobenzo-2oxa-1,3-diazole-4-sulfonate $(1 \mathrm{~g} / 1$ of potassium tetraborate), and incubated at $60^{\circ} \mathrm{C}$ for $60 \mathrm{~min}$. After cooling on ice, a sample volume of $15 \mu 1$ was subjected to high-performance liquid chromatography analysis and detected by a fluorescence detector (Waters 474, USA). 


\subsection{Statistical analysis}

We used a chi-square test and Student's $t$-test to evaluate the categorical and continuous variables, respectively. Because of the right-skewed distribution of HCY values, a log transformation was used for normalizing the distribution. We calculated crude and adjusted odds ratios (ORs) plus 95\% confidence intervals (CIs) to evaluate the association of CAD with other variables. We used univariate and multivariate logistic regressions to estimate the association of HCY values with other variables. Tukey's pairwise comparison procedure was used for the comparison of HCY values between groups with one-, two-, and three-vessel disease and non-CAD. To evaluate the risk of CAD, we used age- and sex-adjusted logistic regression to estimate ORs and 95\% CIs for each HCY quartile [24]. We also used linear regression to compare the severity and extent of atherosclerosis between HCY quartiles. A significant difference was defined at $P<0.05$. Data analysis was performed with SAS Statistical Software (SAS Institute, Cary, NC).

\section{Results}

\subsection{Subjects}

There were 142 men (74\%) and 50 women $(26 \%)$ (aged 21-93 years; mean, $59 \pm 9$ years). A total of 86 individuals (45\%) had hypertension and $35(18 \%)$ had diabetes mellitus. There were 66 current smokers (34\%), and $64(33 \%)$ had hypercholesterolemia with $22(11 \%)$ taking lipid-lowering drugs (Table 1). There were 23 $(12 \%)$ with obesity and five $(3 \%)$ with a family history of CAD, and three patients $(2 \%)$ had a history of ischemic stroke. The CAD group consisted of 116 patients (aged 36-93 years; mean $61 \pm 10$ years), including $51(27 \%)$ with three-, $20(10 \%)$ with two-, and $45(23 \%)$ with one-vessel disease. The remaining of 76 $(40 \%)$ subjects were free of significant stenosis (aged 21-84 years; mean $56 \pm 12$ years). A total of 65 CAD patients (27 with three-, ten with two-, and 28 with one-vessel disease) were diagnosed in the 70 subjects with stable angina. All 15 individuals with unstable angina had CAD (nine with three-, three with two-, and

Table 1

Crude and adjusted odds ratios for coronary artery disease associated with selective risk factors ${ }^{\mathrm{a}}$

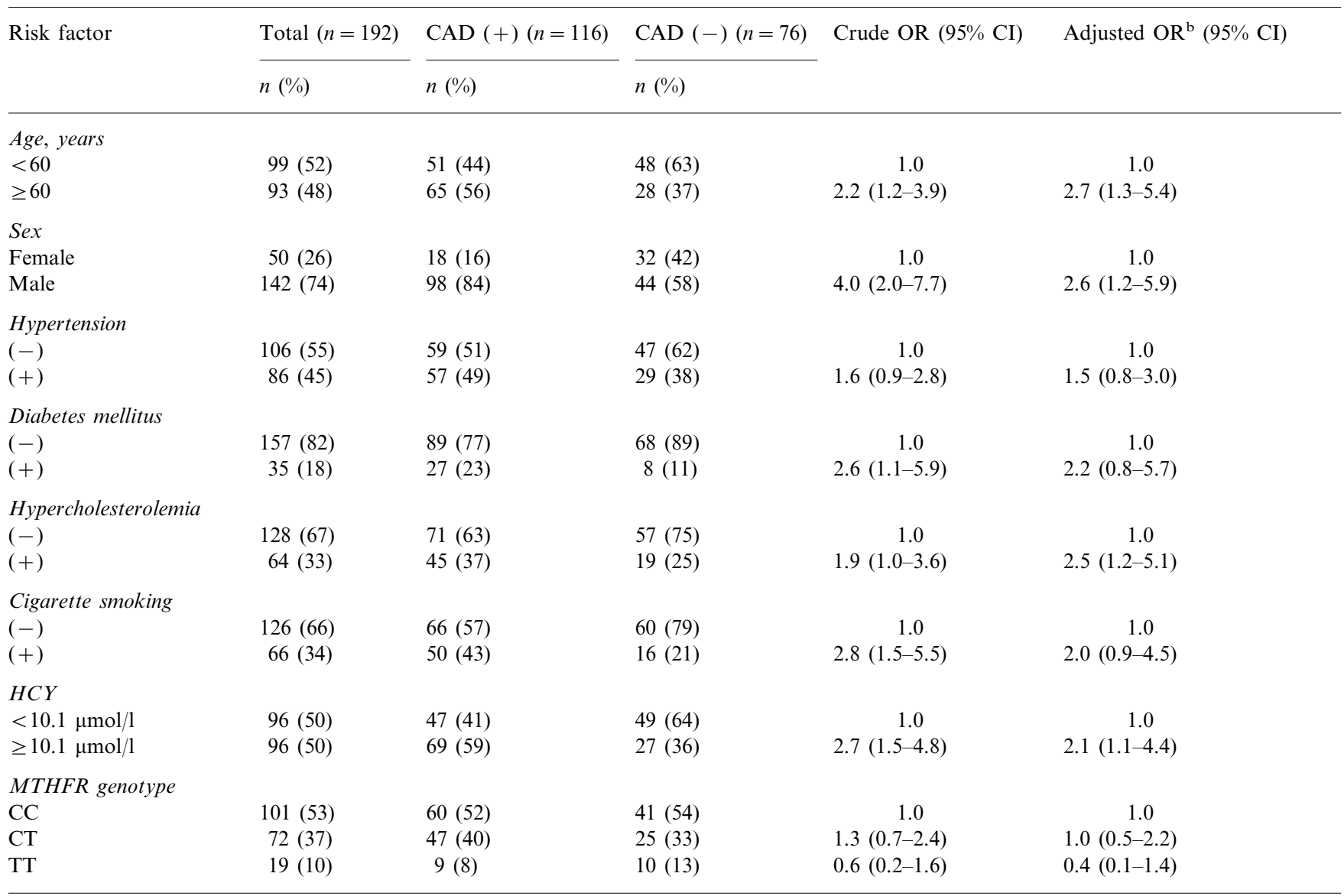

${ }^{\text {a }} \mathrm{CAD}$, coronary artery disease; $\mathrm{CC}$, non-thermolabile homozygotes; CI, confidence interval; CT, thermolabile heterozygotes; HCY, homocysteine; MTHFR, methylenetetrahydrofolate reductase; OR, odds ratio; TT, thermolabile homozygotes.

${ }^{\mathrm{b}}$ Multiple variable logistic regression analysis. 
Table 2

Univariate and multivariate determinants of plasma homocysteine levels ${ }^{\mathrm{a}}$

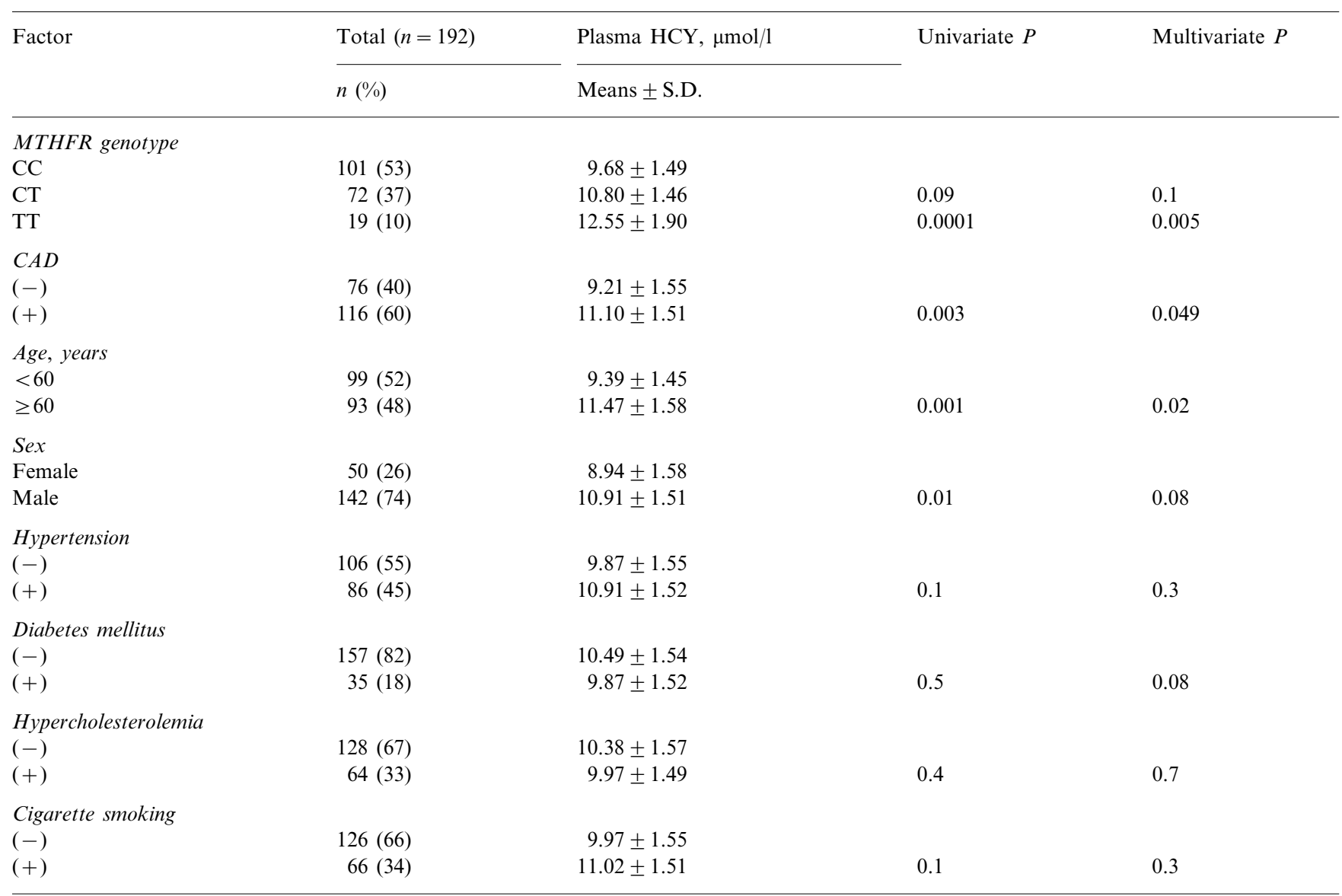

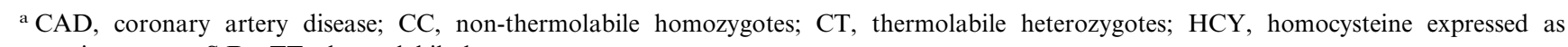
geometric means \pm S.D.; TT, thermolabile homozygotes.

three with one-vessel disease). Among the 31 persons for prognostic stratification of myocardial infarction, there were 15 patients with three-, seven with two-, and nine with one-vessel disease. A total of four patients (one-vessel disease) were found in the group of 42 subjects with atypical chest pain. Only one patient (one-vessel disease) came from the group consisting of 34 persons with other heart diseases. The mean severity and extent scores were $38.9 \pm 28.6$ and $38.1 \pm 19.5$, $35.7 \pm 22.3$ and $38.7 \pm 14.1,41.2 \pm 23.4$ and $39.1 \pm$ $15.0,3.7 \pm 9.5$ and $4.3 \pm 7.4$, and $1.5 \pm 3.2$ and $4.2 \pm$ 7.3 in the individuals with stable angina, unstable angina, prognostic stratification of myocardial infarction, atypical chest pain and other heart diseases, respectively.

\subsection{Risk factors of $C A D$}

Univariate analysis showed that CAD was associated with the older age group ( $\geq 60$ years), male individuals, diabetic and hypercholesterolemic patients, smokers, and subjects with HCY $\geq 10.1 \mu \mathrm{mol} / 1$ (median value).
Multivariate analysis revealed an elevated risk of CAD for the elderly, males, and individuals with hypercholesterolemia and HCY $\geq 10.1 \mu \mathrm{mol} / 1$ (Table 1 ). There was no significant difference in the distribution of MTHFR genotypes between CAD and non-CAD groups. Homozygosity was noted in nine $(8 \%)$ of 116 CAD patients and ten $(13 \%)$ of 76 non-CAD subjects $(P=0.33$; $95 \% \mathrm{CI}, 0.2-1.6)$. The T-allele frequency in the entire population was 0.29 ( 0.28 for CAD and 0.30 for nonCAD, $P=0.74)$.

\subsection{Determinants of $\mathrm{HCY}$ levels}

Univariate logistic regression indicated that $\mathrm{HCY}$ levels were significantly higher in the TT genotype, $\mathrm{CAD}$, elderly, and male groups. In multivariate logistic regression, higher HCY levels were independently associated with the TT genotype, CAD, and old age (Table 2). The HCY levels (geometric means) were $12.55 \pm$ $1.60,12.18 \pm 1.42,9.68 \pm 1.43$, and $9.21 \pm 1.55 \mu \mathrm{mol} / 1$ in the groups of three-, two-, one-vessel disease and non-CAD, respectively (Table 3 ). There were signifi- 
cantly higher HCY levels in three-vessel (vs. one-vessel and non-CAD) and two-vessel groups (vs. non-CAD) $(P<0.05$ for both). The HCY levels were $11.70 \pm 1.51$ and $9.39 \pm 1.46 \mu \mathrm{mol} / 1$ in CAD patients with $(n=89)$ and without $(n=27)$ severe stenosis $(\geq 90 \%)$, respectively. The HCY level was significantly higher in patients with severe stenosis as compared to non-CAD subjects $(P=0.005)$. However, there was no significant difference in HCY levels between CAD patients with stenosis less than $90 \%$ and non-CAD subjects $(P=$ $0.44)$.

\subsection{Relationship of HCY levels to CAD risk and atherosclerosis}

The HCY distribution in our sample was skewed toward higher values, with the 95th, 90th, 75th, 50th, and 25th percentiles at 20.6, 17.8, 13.9, 10.0, and 7.9 $\mu \mathrm{mol} / 1$, respectively, and a maximum and a minimum of 55.0 and $3.0 \mu \mathrm{mol} / 1$. The value of the 95 th percentile in non-CAD subjects was $16.2 \mu \mathrm{mol} / \mathrm{l}$. Table 4 shows that subjects in the top two HCY quartiles ( $\geq 14.0$ and $10.1-13.9 \mu \mathrm{mol} / 1)$ were $4.0(95 \% \mathrm{CI}, 1.7-9.2)$ and 3.2 (95\% CI, 1.4-7.4) times more likely to have CAD than those in the lowest HCY quartile $(\geq 7.9 \mu \mathrm{mol} / \mathrm{l})(P=$ 0.001 and 0.007 , respectively). However, there was no significant difference in CAD risk between the two lower HCY quartiles. The severity score and extent score had significant correlations with HCY quartiles by linear regression analysis $(P=0.0001$ for both).

\section{Discussion}

In our Taiwanese subjects, the allele frequency of MTHFR $677 \mathrm{C} \rightarrow \mathrm{T}$ mutation (0.29) and the frequency of the three genotypes (CC 53\%, CT 37\%, and TT 10\%) were similar to those reported by McAndrew et al. [25] and $\mathrm{Ma}$ et al. [26]. However, the frequency of homozygous mutation may vary between different populations. Morita et al. [10] reported a 16\% homozygous frequency in Japanese CAD patients, $8 \%$ higher than in ours. The result of our study does not support the $677 \mathrm{C} \rightarrow \mathrm{T}$ mutation as a CAD risk factor. Several recent studies also showed no associations between
MTHFR polymorphism and CAD [12,14,26,27]. One possible reason for these inconsistencies may be associated with differences in the ethnicity of the study subjects. MTHFR mutation exerts its influence on atherosclerosis through the action of HCY. However, the plasma HCY concentration is not only influenced by the gene mutation but also by non-genetic factors, such as folate status. Though homozygous mutation is associated with increased HCY levels in those with low folate levels [13,28], the effect of this genetic defect may be largely compensated by adequate folate intake $[13,26]$. The nutritional compensation may make a substantial difference between HCY concentrations in those with homozygous mutation. This might be another reason for the inconsistency between MTHFR mutation and CAD. It has been shown that the TT genotype has higher plasma HCY concentrations in our study. It is well established that an elevated plasma HCY level is a risk factor for atherosclerosis $[29,30]$. Therefore, individuals with the TT genotype may be at an increased risk for CAD. As the genetic mutation accounts only for a fraction of the variation in plasma HCY concentrations, a much larger sample size might be necessary to demonstrate a genotype-related risk than to show the risk associated with plasma HCY concentrations. Perhaps a longer study with multivariate analysis to dissect out confounding variables (e.g. folate intake) would be needed to clarify the association between MTHFR mutation and CAD.

Our study showed a positive relationship between plasma HCY and CAD, revealing significantly higher HCY levels in patients with multi-vessel disease or severe stenosis $(\geq 90 \%)$. von Eckardstein et al. [17] reported a similar result for the relationship between HCY levels and the number of stenosed vessels. A positive association between the HCY level and severe coronary atherosclerosis $(\geq 90 \%)$ has also been reported by Verhoef et al. [31]. However, some previous studies [16,27] reported no significant correlation between CAD severity and HCY levels. These conflicting results might be associated with the different definitions of stenosis severity between studies ( $\geq 70 \%$ by Kang et al. [16] and $\geq 50 \%$ by Wilken et al. [27]). Further scrutiny might be necessary to clarify the relationship between HCY concentrations and less severe stenosis

Table 3

Comparison of HCY geometric means \pm S.D. between groups of three-, two-, and one-vessel disease and non-CAD ${ }^{\mathrm{a}}$

\begin{tabular}{lllll}
\hline & Three-vessel $(n=51)$ & Two-vessel $(n=20)$ & One-vessel $(n=45)$ & Non-CAD $(n=76)$ \\
\hline $\mathrm{HCY}, \mu \mathrm{mol} / 1$ & $12.55 \pm 1.60^{*}$ & $12.18 \pm 1.42^{\dagger, *}$ & $9.68 \pm 1.43^{*,+}$ & $9.21 \pm 1.55^{*, \dagger}$ \\
\hline
\end{tabular}

\footnotetext{
${ }^{\text {a }} \mathrm{CAD}$, coronary artery disease; HCY, homocysteine.

* Three-vessel versus one-vessel and non-CAD, $P<0.05$.

${ }^{\dagger}$ Two-vessel versus non-CAD, $P<0.05$.

* Two-vessel versus one-vessel, $P=$ NS.
} 
Table 4

Age- and sex-adjusted association of HCY quartiles with CAD risk and atherosclerosis ${ }^{\mathrm{a}}$

HCY quartile (range, $\mu \mathrm{mol} / \mathrm{l}$ )

I (3.3-7.9) $n=48 \quad$ II (8.0-10.0) $n=48 \quad$ III (10.1-13.9) $n=46$

IV $(14.0-55.0) n=50$

\begin{tabular}{|c|c|c|c|c|}
\hline $\mathrm{CAD}(+), n(\%)$ & $20(41)$ & $27(56)$ & $32(70)$ & $37(74)$ \\
\hline OR $(95 \% \mathrm{CI})$ & 1.0 & $1.8(0.8-4.0)$ & $3.2(1.4-7.4)$ & $4.0(1.7-9.2)$ \\
\hline $\begin{array}{l}\text { Severity score } \\
\text { Mean } \pm \text { S.D. }\end{array}$ & $15.0 \pm 21.4$ & $15.4 \pm 20.0$ & $30.1 \pm 26.5$ & $38.5 \pm 29.0$ \\
\hline Linear regression & & Parameter & S.E. & $P$-value \\
\hline $\begin{array}{l}\text { Intercept } \\
\text { HCY quartile }\end{array}$ & & $\begin{array}{l}3.4 \\
8.5\end{array}$ & $\begin{array}{l}4.3 \\
1.6\end{array}$ & 0.0001 \\
\hline $\begin{array}{l}\text { Extent score } \\
\text { Mean } \pm \text { S.D. }\end{array}$ & $16.4 \pm 16.8$ & $18.5 \pm 18.6$ & $26.0 \pm 18.2$ & $39.2 \pm 22.8$ \\
\hline Linear regression & & Parameter & S.E. & $P$-value \\
\hline $\begin{array}{l}\text { Intercept } \\
\mathrm{HCY} \text { quartile }\end{array}$ & & $\begin{array}{l}5.9 \\
7.7\end{array}$ & $\begin{array}{l}3.4 \\
1.2\end{array}$ & 0.0001 \\
\hline
\end{tabular}

${ }^{\text {a }}$ CAD, coronary artery disease; CI, confidence interval; HCY, homocysteine; OR, odds ratio; S.D., standard deviation; S.E., standard error.

(70-90\%). In addition, the inconsistency between the severity of coronary atherosclerosis and HCY concentrations may result from oversimplification of the atherosclerotic burden by estimating significant stenosis only. To better elucidate the correlation between the HCY concentrations and the severity of coronary stenosis, we employed the Gensini score to quantify the total atherosclerotic burden. The traditional classification of one-, two- and three-vessel disease used to categorize the severity of CAD is convenient, but may underestimate the amount of myocardium in jeopardy [32]. The Gensini score has been shown to provide a satisfactory functional stratification of coronary stenosis $[20,21]$. Recent studies have shown that coronary events are related to the progression of mild atherosclerosis and the rupture of minor plaques [18,33-35]. Pathologic findings have also revealed that more than $50 \%$ of the coronary tree is usually covered by raised atheroma before a clinical event occurs [35,36]. Sullivan et al. [22] and Nakagomi et al. [37] developed an extent score to reflect the load of minor plaques, which improved correlation with conventional CAD risk factors and was significantly related to the Gensini scoring severity of coronary disease. Therefore, evaluating the severity and extent of total atherosclerosis burden becomes important in conveying prognostic information. Our study showed that both the severity score and the extent score had good correlation with HCY quartiles. To our knowledge, we are the first to demonstrate the relationship between HCY levels and the severity and extent of coronary atherosclerosis, and we propose that hyperhomocysteinemia has a continuous influence on the initiation and progression of coronary atherosclerosis. Our study is limited to the use of coronary angiog- raphy for determining both the severity and extent of atherosclerosis. This method may lack accuracy as compared to the use of intravascular ultrasound. However, it is not practical to use intravascular ultrasound to evaluate the entire coronary tree; coronary angiography is still the most readily available clinical method [37].

Our data showed that elevated HCY $(\geq 10.1 \mu \mathrm{mol} / \mathrm{l})$ has a graded effect on the risk of CAD. The subjects in the top two HCY quartiles $(\geq 14.0$ and $10.1-13.9$ $\mu \mathrm{mol} / \mathrm{l})$ were 4.0 and 3.2 times more likely to have CAD than those in the lowest quartile $(\leq 7.9 \mu \mathrm{mol} / 1)$, respectively. This graded effect was similar to that in previous reports [30,31,38]. Glueck et al. [38] found that the relative risk for atherosclerotic events was 2.7 and 3.8 times higher in the top two HCY deciles $(\geq 13.1$, $\geq 11.4 \mu \mathrm{mol} / \mathrm{l})$. Boushey et al. [30] reported that the OR for CAD with a $5-\mu \mathrm{mol} / 1 \mathrm{HCY}$ increment was 1.6 for men and 1.8 for women. Adequate dietary folate intake may be recommended for individuals (especially in elderly males) with $\mathrm{HCY} \geq 10.1 \mu \mathrm{mol} / \mathrm{l}$.

The present study suggests that an elevated plasma HCY level, but not MTHFR mutation, is implicated as a risk factor for CAD. Hyperhomocysteinemia appears to have a graded effect on the risk of CAD as well as the severity and extent of atherosclerosis.

\section{Acknowledgements}

This study was supported by a grant from the National Science Council (NSC 87-2314-B-002-214) and a grant from the University Research Fund (87S1514). 


\section{References}

[1] Stampfer MJ, Malinow MR, Willett WC, Newcomer LM, Upson B, Ullmann D, et al. A prospective study of plasma homocyst(e)ine and risk of myocardial infarction in US physicians. J Am Med Assoc 1992;268:877-81.

[2] Mayer EL, Jacobsen DW, Robinson K. Homocysteine and coronary atherosclerosis. J Am Coll Cardiol 1996;27:517-27.

[3] McCully KS. Homocysteine and vascular disease. Nat Med 1996;2:386-9.

[4] Kang SS, Wong PWK, Norusis M. Homocysteinemia due to folate deficiency. Metabolism 1987;36:458-62.

[5] Kang SS, Zhou J, Wong PWK, Susmano A, Sora J, Norusis M, et al. Thermolabile methylenetetrahydrofolate reductase: an inherited risk factor for coronary artery disease. Am J Hum Genet 1991;48:536-45.

[6] Engbersen AM, Franken DG, Boers GH, Stevens EMB, Trijbels FJM, Blom GHJ. Thermolabile 5,10-methylenetetrahydrofolate reductase as a cause of mild hyperhomocysteinemia. Am J Hum Genet 1995;56:142-50.

[7] Goyette P, Sumner JS, Milos R, Duncan AMV, Rosenblatt DS, Matthews RG, et al. Human methylenetetrahydrofolate reductase: isolation of cDNA, mapping and mutation identification. Nat Genet 1994;7:195-200.

[8] Goyette P, Frosst P, Rosenblatt DS, Rozen R. Seven novel mutations in the methylenetetrahydrofolate reductase gene and genotype/phenotype correlations in severe methylenetetrahydrofolate reductase deficiency. Am J Hum Genet 1995;56:1052-9.

[9] Frosst P, Blom HJ, Milos R, Goyette P, Sheppard CA, Matthews RG, et al. A candidate genetic risk factor for vascular disease: a common mutation in methylenetetrahydrofolate reductase. Nat Genet 1995;10:111-3.

[10] Morita H, Taguchi JI, Kurihara H, Kitaoka M, Kaneda H, Kurihara Y, et al. Genetic polymorphism of 5,10-methylenetetrahydrofolate reductase (MTHFR) as a risk factor for coronary artery disease. Circulation 1997;95:2032-6.

[11] Kluijtmans LAJ, Kastelein JJP, Lindemans J, Boers GHJ, Heil SG, Bruschke AVG, et al. Thermolabile methylenetetrahydrofolate reductase in coronary artery disease. Circulation 1997;96:2573-7.

[12] Brugada R, Marian AJ. A common mutation in methylenetetrahydrofolate reductase gene is not a major risk of coronary artery disease or myocardial infarction. Atherosclerosis 1997; 128:107-12.

[13] Van Bockxmeer FM, Mamotte CDS, Vasikaran SD, Taylor RR. Methylenetetrahydrofolate reductase gene and coronary artery disease. Circulation 1997;95:21-3.

[14] Anderson JL, King GJ, Thomson MJ, Todd M, Bair TL, Muhlestein JB, et al. A mutation in the methylenetetrahydrofolate reductase gene is not associated with increased risk for coronary artery disease or myocardial infarction. J Am Coll Cardiol 1997;30:1206-11.

[15] Malinow MR, Nieto FJ, Szklo M, Chambless LE, Bond G. Carotid artery intimal-medial wall thickening and plasma homocyst(e)ine in asymptomatic adults. The atherosclerosis risk in communities study. Circulation 1993;87:1107-13.

[16] Kang SS, Passen EL, Ruggie N, Wong PWK, Sora H. Thermolabile defect of methylenetetrahydrofolate reductase in coronary artery disease. Circulation 1993;88(1):1463-9.

[17] von Eckardstein A, Malinow MR, Upson B, Heinrich J, Schulte $\mathrm{H}$, Schönfeld R, et al. Effects of age, lipoproteins, and hemostatic parameters on the role of homocyst(e)inemia as a cardiovascular risk factor in men. Arterioscler Thromb 1994;14:460-4.

[18] Brown BG, Zhao XQ, Sacco DE, Albers JJ. Lipid lowering and plaque regression. New insights into prevention of plaque disruption and clinical events in coronary disease. Circulation 1993;87:1781-91.
[19] Austen WG, Edwards JE, Frye RL, Gensini GG, Gott VL, Griffith LSC, et al. AHA Committee Report: a reporting system on patients evaluated for coronary artery disease. Report of the Ad Hoc Committee for grading of coronary artery disease, Council on Cardiovascular Surgery, American Heart Association. Circulation 1975;51:7-40.

[20] Gensini GG. A more meaningful scoring system for determining the severity of coronary heart disease. Am J Cardiol 1983;51:606.

[21] Chao CL, Huang PJ, Wu CC, Shen SJ, Chieng PU, Su CT, et al. Correlation between quantitative severity of stress thallium-201 myocardial perfusion defect and severity of coronary stenosis. J Formos Med Assoc 1996;95:105-9.

[22] Sullivan DR, Marwick TH, Freedman SB. A new method of scoring coronary angiograms to reflect extent of coronary atherosclerosis and improve correlation with major risk factors. Am Heart J 1990;119:1262-7.

[23] Fortin LJ, Genest J Jr. Measurement of homocyst(e)ine in the prediction of atherosclerosis. Clin Biochem 1995;28:155-62.

[24] Schwartz SM, Siscovick DS, Malinow MR, Rosendaal FR, Beverly RK, Hess DL, et al. Myocardial infarction in young women in relation to plasma total homocysteine, folate, and a common variant in the methylenetetrahydrofolate reductase gene. Circulation 1997;96:412-7.

[25] McAndrew PE, Brandt JT, Pearl DK, Prior TW. The incidence of the gene for thermolabile methylenetetrahydrofolate reductase in African Americans. Thromb Res 1996;83:195-8.

[26] Ma J, Stampfer MJ, Hennekens CH, Frosst P, Selhub J, Horsford $\mathrm{J}$, et al. Methylenetetrahydrofolate reductase polymorphism, plasma folate, homocysteine, and risk of myocardial infarction in US physicians. Circulation 1996;94:2410-6.

[27] Wilcken DEL, Wang XL, Sim AS, McCredie RM. Distribution in healthy and coronary populations of the methylenetetrahydrofolate reductase (MTHFR) $\mathrm{C}_{677} \mathrm{~T}$ mutation. Arterioscler Thromb Vasc Biol 1996;16:878-82.

[28] Jacques PF, Bostom AG, Williams RR, Ellison RC, Eckfeldt JH, Rosenberg IH, et al. Relation between folate status, a common mutation in methylenetetrahydrofolate reductase, and plasma homocysteine concentrations. Circulation 1996;93:7-9.

[29] Boers GHJ, Smals AGH, Trijbels FJM, Fowler B, Bakkeren JAJM, Schoonderwaldt HC, et al. Heterozygosity for homocystinuria in premature peripheral and cerebral occlusive arterial disease. N Engl J Med 1985;313:709-15.

[30] Boushey CJ, Beresford SAA, Omenn GS, Motulsky AG. A quantitative assessment of plasma homocysteine as a risk factor for vascular disease: probable benefits of increasing folic acid intakes. J Am Med Assoc 1995;274:1049-57.

[31] Verhoef P, Kok FJ, Kruyssen DACM, Schouten EG, Witteman JCM, Grobbee DE, et al. Plasma total homocysteine, B vitamins, and risk of coronary atherosclerosis. Arterioscler Thromb Vasc Biol 1997;17:989-95.

[32] Hutter AM Jr. Is there a left main equivalent? Circulation 1980;62:207-11.

[33] Azen SP, Mack WJ, Cashin-Hemphill L, LaBree L, Shircore AM, Selzer RH, et al. Progression of coronary artery disease predicts clinical coronary events: long-term follow-up from the Cholesterol Lowering Atherosclerosis Study. Circulation 1996;93:34-41.

[34] The LCAS Investigators, Herd JA, Ballantyne CM, Farmer JA, Ferguson J III, Jones PH, West MS, et al. Effects of fluvastatin on coronary atherosclerosis in patients with mild to moderate cholesterol elevations (Lipoprotein and Coronary Atherosclerosis Study [LCAS]). Am J Cardiol 1997;80:278-86.

[35] Falk E. Why do plaques rupture? Circulation 1992;86(Suppl III):30-42.

[36] Solberg LA, Strong JP. Risk factors and atherosclerosis: a review of autopsy studies. Arteriosclerosis 1983;3:187-98. 
[37] Nakagomi A, Celermajer DS, Lumley T, Freedman SB. Angiographic severity of coronary narrowing is a surrogate marker for the extent of coronary atherosclerosis. Am J Cardiol 1996;78:516-9.
[38] Glueck CJ, Shaw P, Lang JE, Tracy T, Sieve-Smith L, Wang Y. Evidence that homocysteine is an independent risk factor for atherosclerosis in hyperlipidemic patients. Am $\mathbf{J}$ Cardiol 1995;75:132-6. 